\title{
Durmeval Trigueiro Mendes e sua contribuição à pós-graduação em educação
}

\author{
Maria de Lourdes de Albuquerque Fávero \\ Universidade Católica de Petrópolis, Mestrado em Educação \\ Universidade Federal do Rio de Janeiro, Programa de Estudos e Documentação Educação e Sociedade
}

\section{O itinerário do educador}

Ao falar sobre a contribuição de Durmeval Trigueiro Mendes à pós-graduação é oportuno ressaltar que se trata de um pensador e educador que foi, para quantos tiveram o privilégio de conviver com ele, estímulo à reflexão e à pesquisa. Mostrava-se, também, um intelectual consciente de sua responsabilidade com a construção do pensamento educacional brasileiro e com o processo de democratização da educação no país. Nessa perspectiva, ele próprio, em depoimento concedido à Revista ANDE, se declarou mobilizado por duas grandes paixões intelectuais: “a filosofia e a política, isto é, o fato político, a mecânica do poder, especialmente do Estado, os protagonistas e sobretudo o processo político” (Trigueiro Mendes, 1983, p. 29). Comentando sua trajetória, registra nesse depoimento:

[...] minha transmutação filosófica teve início na juventude, pela manifestação de algumas categorias: consciência, sujeito/objeto, experiência e depois, mais profundamente, a práxis, a totalidade e a vontade política, e com esta última, saindo do exílio, entrei no fato político. (idem, ibidem)
Para Durmeval, “o ato de pensar é, até certo ponto, um ato de vontade política; para ver é preciso acreditar no próprio poder de ver” (Trigueiro Mendes, 1990, p. 41).

Partindo dessas colocações e tendo presente que em 2006 comemoraremos quarenta anos de pós-graduação stricto sensu em educação, no Brasil, ${ }^{1}$ não poderíamos deixar de destacar o significado e a contribuição de Durmeval Trigueiro na construção desse nível de educação superior como professor, pesquisador e homem de ação. Neste trabalho, procuraremos assinalar sua constante dedicação ao canalizar o melhor de seus esforços para o universo acadêmico, especialmente para a pós-graduação em educação, na qual atuou como docente-pesquisador no período que se estendeu de 1970 a 1987, quando faleceu, aos 60 anos.

1 O primeiro curso de mestrado em educação foi implantado em 1966, na Pontifícia Universidade Católica do Rio de Janeiro (PUC-Rio). 
Durmeval Trigueiro tinha apenas 24 anos (1951) quando iniciou sua vida pública, exercendo o cargo de secretário de Educação da Prefeitura de Campina Grande, no estado da Paraíba, e, no ano seguinte, o de diretor do Departamento de Educação do mesmo estado. Nesse período começa também sua carreira no magistério, como catedrático de sociologia da educação, na Faculdade de Filosofia da Paraíba, e como professor de história e filosofia da educação, no Instituto de Educação. Quando tinha 26 anos (1954), o governador José Américo de Almeida convidou-o para dirigir a Secretaria de Educação e Cultura dessa unidade federativa. Nessa função, o governador o incumbiu de organizar a Universidade da Paraíba, sendo escolhido pelo conselho universitário, em 1956, como seu primeiro reitor. Deixando esses cargos em 1957, realizou viagem de quase um ano à Europa, a convite dos governos da França e da Alemanha, observando o sistema educacional desses países e visitando também universidades inglesas.

Convocado por Anísio Teixeira, na ocasião diretor do Instituto Nacional de Estudos Pedagógicos (INEP), Durmeval transferiu-se para o Rio de Janeiro em 1958, para assumir o cargo de supervisor da Campanha de Educação Complementar, no Ministério da Educação e Cultura (MEC)/INEP (Trigueiro Mendes, 1983, p. 30). Nesse ano tem seu primeiro contato com a Pontifícia Universidade Católica do Rio de Janeiro (PUC-Rio), lecionando filosofia da educação no curso de pedagogia. A partir daí, concentra suas atividades profissionais no Rio de Janeiro. Por indicação de Anísio Teixeira ao ministro da Educação Oliveira Britto, foi nomeado diretor do ensino superior do MEC, num período bastante conturbado da história do país (1961-1964). Em 1964, um pouco antes do golpe militar, foi indicado para integrar o Conselho Federal de Educação (CFE), no qual permaneceu até setembro de 1969.

Em 1965, assumiu a cadeira de história do pensamento econômico, na Faculdade de Ciências Econômicas da Universidade do Estado da Guanabara (UEG) - atual Universidade do Estado do Rio de Janeiro (UERJ) -, e, mais tarde, a cadeira de sociologia na Faculdade de Administração e Finanças da mesma universidade. Em 1968, obteve transferência da Universidade Federal da Paraíba (UFPB) para a Universidade Federal do Rio de Janeiro (UFRJ), assumindo a cadeira de sociologia da educação na Faculdade de Educação.

Em setembro de 1969, em pleno regime militar, foi atingido pelo Ato Institucional $n^{0} 5$ (AI-5), que o aposentou compulsoriamente de todas as funções públicas. Durante cerca de dez anos não exerceu qualquer atividade pública. Somente em 1980 foi reintegrado como técnico do MEC e professor universitário. Nesse período, dedicou a maior parte de seu tempo aos mestrados de educação do Instituto de Estudos Avançados em Educação da Fundação Getúlio Vargas (IESAE-FGV) e da PUC-Rio.

Embora Durmeval afirmasse que "não sabia precisamente o fato determinante de sua aposentadoria”, tudo leva a crer que deve ter pesado seu posicionamento, no CFE, explicitamente contrário à inserção nos currículos da disciplina educação moral e cívica, quando a questão foi posta mediante aviso do ministro da Guerra, Costa e Silva, para o ministro da Educação, propondo que essa disciplina fosse incluída no currículo. Por sua vez, o ministro enviou ofício ao CFE para posicionamento deste (idem, p. 32). Segundo Durmeval:

[...] o CFE capitulou frente ao poder, materializado pela presença intimidadora de militares fardados assistindo à sessão plenária do Conselho. O Presidente procedeu à votação, e [...] todos os conselheiros votaram favoravelmente à inserção no currículo da disciplina Educação Moral e Cívica. Todos, menos eu. (idem, ibidem)

Com relação à aposentadoria compulsória de Durmeval, é de toda pertinência registrar o ofício do Conselho Departamental, da Faculdade de Educação da UFRJ, registrado na Ata da $23^{\mathrm{a}}$ reunião desse conselho, datada de 7 de outubro de 1969:

Ilustre colega e prezado amigo.

O Conselho Departamental da Faculdade de Educa- 
ção (UFRJ), reunido terça-feira última, aprovou unanimemente um voto, para ser consignado em ata e que exprime o quanto lamenta o seu afastamento da atividade docente nesta casa, embora não haja perdido a esperança de possível retificação do ato que o determinou. Durante o ano que o nobre colega, transferido da Universidade Federal da Paraíba, prestou sua colaboração a esta Faculdade, no exercício didático, na chefia de um dos departamentos e na participação no Conselho Departamental, sua conduta só fez nascerem as razões de apreço e de admiração com que fora recebido, em face do renome de educador que já o consagrava, pelos seus trabalhos publicados e pela sua atuação em outras Universidades, na Diretoria do Ensino Superior e no CFE. Sentimos e sentiremos a falta de seu convívio cordial, inteligente e construtivo. Creia outrossim, o ilustre colega, que me é grato pessoalmente transmitir-lhe este voto do Conselho Departamental, que também é meu, como Diretor da Faculdade e como colega, atentos ao valor de sua personalidade e as boas recordações de nosso trabalho em comum. Com alto apreço, subscrevo-me, colega e admirador.

Professor Raul Bittencourt - Diretor Pró-Tempore (Faculdade..., 1969, p. 32-33)

Lembra Márcia Trigueiro Mendes (1990, p. 190) ter sido esse o único colegiado, “de todos os que Durmeval integrava, a se manifestar publicamente contra a sua punição", acrescentando: "fatos como esse não são esquecidos, ganham relevo na memória de quem passa pela experiência de ostracismo durante uma ditadura militar”.

\section{A contribuição de Durmeval Trigueiro à pós-graduação em educação}

Embora a pós-graduação em educação no Brasil, em sentido estrito, tenha início em 1966, com o curso de mestrado da PUC-Rio, havia antes, por parte dessa universidade, uma preocupação institucional que foi implantada pela antiga Faculdade de Filosofia, objetivando preparar no exterior seus futuros quadros docentes e de pesquisa em pós-graduação. Como parte dessa proposta, foi celebrado em 1965 um convênio com a Diretoria do Ensino Secundário do MEC, surgindo, de um lado, a possibilidade de contratação de professores que retornavam do exterior para o curso de pedagogia, em tempo integral, e, de outro, a organização de um curso de especialização em planejamento educacional, uma das primeiras iniciativa concretas na área (Carvalho \& Fávero, 1986). ${ }^{2}$

Ainda em 1965 é planejado, na PUC-Rio, um programa conjunto de psicologia e pedagogia, que deu origem ao curso de mestrado em educação, iniciado no ano seguinte, com duas áreas de concentração: aconselhamento psicopedagógico, articulada estreitamente com professores da psicologia, e planejamento da educação. Essa segunda área de concentração não contava com professores e pesquisadores exclusivos dessa universidade; utilizava recursos humanos externos, sem doutorado mas com experiência profissional na área de planejamento educacional (Pontifícia..., 1986, p. 1). Vale observar que os primórdios da área de planejamento educacional, em 1965, foram assim constituídos com vista à sedimentação de seus quadros e com a previsão de que o CFE estava prestes a estabelecer diretrizes para a pós-graduação stricto sensu, o que de fato ocorreu com o parecer $\mathrm{n}^{\circ}$ 977/65, que teve como relator o conselheiro Newton Sucupira.

Entre 1968 e 1970, com a equipe de planejamento universitário da PUC-Rio, coordenada por Paulo de Assis Ribeiro, essa segunda área de concentração do mestrado passa por modificações e ajustamentos teórico-metodológicos, procurando sintonizar o caráter acadêmico peculiar a um programa de pós-graduação stricto sensu com os interesses profissionais dos mestrandos, que buscavam uma formação teórico-prática.

${ }^{2}$ Durmeval atuou também como membro do grupo de trabalho de reestruturação da UEG - atual UERJ -, em 1969, organizando e coordenando um dos primeiros cursos de especialização em planejamento educacional no país (Fávero, 2000, p. 8). 


\section{Durmeval na pós-graduação em educação da PUC-Rio}

Foi na PUC-Rio, como professor do Departamento de Educação e coordenador da área de planejamento educacional no curso de mestrado em educação, que Durmeval reiniciou, em 1970, suas atividades como docente-pesquisador. Mas foi sobretudo a partir de 1971 que a disciplina planejamento educacional, obrigatória e desenvolvida em dois semestres, valendo três créditos cada, além de um estágio de quatro créditos, passou a constituirse na espinha dorsal do curso. De um lado, a disciplina procurava amadurecer a perspectiva teóricometodológica e propor uma discussão mais conseqüente e aprofundada sobre:

a) a semântica do planejamento, tanto nas sociedades socialistas como nas capitalistas;

b) os pressupostos teóricos do planejamento e sua relação com a educação;

c) as diferentes metodologias e a relação administração-planejamento.

Por sua vez, o estágio objetivava proporcionar contato direto dos mestrandos com as agências de planejamento, acompanhar e realizar um exercício concreto de planejamento, propiciando uma relação fertilizadora entre teoria e prática (Carvalho \& Fávero, 1986, p. 5).

Sobre a concepção de política e planejamento educacional, as principais contribuições de Durmeval foram elaboradas desde o período em que esteve no CFE, a partir de estudos e pareceres, assim como no período em que atuou nos Colóquios Estaduais sobre Organização dos Sistemas de Educação (CEOSE), de 1966-1969, integrado por peritos da Organização das Nações Unidas para a Educação, a Ciência e a Cultura (UNESCO) e especialistas brasileiros, prestando cooperação técnica a vários estados em matéria de planejamento, organização educacional e reestruturação dos sistemas educacionais. A experiência acumulada nos diversos cargos que ocupou muito contribuiu para que Durmeval associasse "a prática do planejamento à sua teorização, fertilizadas ambas pela política, e aprofundadas a partir de uma sólida análise filosófica” (Fávero, 2000, p. 8).

Essas contribuições encontram-se sistematizadas no livro Toward a theory of educational planing: the Brazilian case, editado pelo Latin American Studies Center da Michigan State University, em 1972, e publicado pela Editora da UERJ, em 2000, com o título O planejamento educacional no Brasil (Trigueiro Mendes, 2000). Apesar de escrito há cerca de três décadas, esse livro, segundo Fávero (2000, p. 11):

\section{[...] contém a melhor abordagem sobre planejamento}

educacional brasileiro escrita até hoje. Configura-se também como um privilegiado enfoque teórico do planejamento enquanto processo [...] definido como uma relação dialética entre o poder, instalado no Governo, e o saber produzido por instituições autônomas, entre elas, privilegiadamente, a Universidade.

Durmeval soube relacionar como poucos uma prática de planejamento com sua teorização, marcadas ambas pela política. Para tanto, muito contribuiu, como já assinalado, a experiência nos diversos cargos que ocupou, o que fica patenteado na abordagem da disciplina planejamento educacional, no mestrado de educação da PUC-Rio, no início dos anos de 1970. Com essas preocupações, defendeu uma concepção de planejamento entendida como uma dialética entre o poder e o saber, acrescentando: "o ponto crucial do planejamento é a metodologia que, neste caso, não consiste só num modo de fazer, ou só num modo de pensar, mas em extrair o primeiro do segundo, assim com este daquele" (Trigueiro Mendes, 2000, p. 182).

Nessa linha, seus programas de curso apresentam pontos teóricos fundamentais sobre uma visão de planejamento. Sua preocupação era formar planejadores, e não simples técnicos; formar profissionais críticos comprometidos com os problemas da realidade. A bibliografia utilizada em seus cursos elevava-se a um nível que poderia ser reconhecido 
como o dos atuais doutorados, sendo assumida com a mesma seriedade por alguns de seus alunos, que passaram a atuar em outros programas de pós-graduação ou assumiram importantes cargos técnicoadministrativos no governo federal, em universidades e secretarias de educação estaduais e municipais.

Como expressão desse trabalho de Durmeval na pós-graduação no mestrado em educação da PUCRio, entre outras, duas dissertações merecem destaque nos anos de 1970: Planejamento educacional e política econômica, de Vera Marina Miranda (1974), e O CFE e o planejamento educacional no Brasil, de José Silvério Baía Horta (1975). ${ }^{3}$

Ainda quanto à relação teoria/prática, é ainda nesse mestrado que, de forma inovadora, procurou tornála um pré-requisito, mediante a práxis, constante do estágio exigido dos mestrandos da área de planejamento educacional. Considerando o planejamento um processo dialético entre poder e saber, tinha consciência de que os órgãos de planejamento do governo federal eram instâncias privilegiadas do poder, e que se deveria conhecer melhor esse poder, para se desenvolver, a partir dele, o saber crítico, característica própria de um curso de pós-graduação stricto sensu. Com essa preocupação, toda uma geração de mestrandos realizou estágios no Instituto de Planejamento e Economia Aplicada (IPEA), no Programa de Expansão e Melhoria do Ensino Médio (PREMEM), no Programa Nacional de Teleducação (PRONTEL), vivenciando um tipo de planejamento que alguns deles criticavam e mais tarde procuravam superar em suas situações de trabalho.

A presença desse pensador/educador, durante mais de quinze anos, na PUC-Rio, foi de grande valia para professores e alunos, na forma de entender o pensamento educacional brasileiro em termos de uma nova concepção de planejamento educacional e oferecendo, também, importantes subsídios para se

${ }^{3}$ A dissertação de José Silvério Baía Horta foi publicada em livro, com o título Liberalismo, tecnocracia e planejamento educacional no Brasil. São Paulo, Cortez e Autores Associados, 1982. apreender o que se deveria entender pelo conceito de totalidade, a relação qualidade e quantidade em educação, estabelecendo-a de forma adequada e procurando compreender o significado, o valor e as exigências para que se tenha uma educação efetivamente democrática.

\section{Durmeval e seu legado ao mestrado em educação da FGV}

Em $1^{\circ}$ de junho de 1971, mediante a portaria $n^{\circ}$ 33, assinada pelo presidente da FGV, foi criado o Instituto de Estudos Avançados em Educação, tendo por objetivo "a realização de estudos, pesquisas e ensino em nível de pós-graduação na área de educação”. A mesma portaria designa, também, os membros que constituiriam a Comissão de Planejamento e Programação das Atividades do novo instituto: professor Luiz Alves de Mattos, diretor, e os professores Raymundo Moniz Aragão, José Faria Góes Sobrinho e Durmeval Trigueiro Mendes, membros. ${ }^{4}$

Por ocasião da posse dos membros da comissão de planejamento, vários deles se pronunciaram. Durmeval Trigueiro, usando da palavra, assinalou: "No Brasil, ainda estamos na fase da retórica da educação. A retórica nos limita. Temos que nos liberar da fase jurisdicista da educação. Existem leis em excesso, e pouco de prático realizado. [...] O Instituto de Estudos Avançados em Educação buscará conciliar o ensino prático com o teórico. Tentará, quanto possível, minimizar os efeitos nefastos da aplicação única do ensino prático e do ensino teórico”. E adverte: “a FGV não pode repetir o que já é feito, pois muito pouco tem sido feito". ${ }^{5} \mathrm{O}$ primeiro documento a configurar a identidade do IESAE, em termos de objeti-

${ }^{4}$ Anísio Teixeira, importante educador brasileiro, a partir de cujas idéias foi estruturada a proposta de criação desse instituto, já não participava mais dos trabalhos, por haver falecido em 11 de março daquele ano.

${ }^{5}$ Ata da sessão de abertura dos trabalhos do IESAE, de $1^{\circ}$ de julho de 1971. 
vos, visão estrutural, articulação das três áreas de conhecimento - filosofia da educação, análise dos sistemas educacionais e psicologia da educação -, foi longamente debatido e aprovado em 1971 (Trigueiro Mendes, 1983, p. 32).

Em 1972, aos 45 anos, Durmeval sofreu derrame cerebral seguido de afasia. Pacientemente iniciou trabalho de terapia da palavra. Apesar das dificuldades, durante esse período o essencial da disciplina e da área de concentração de planejamento educacional na PUC-Rio foi mantida, com a participação de outros colegas professores. Ainda se recuperando do derrame, retoma as atividades nesse mestrado e volta a trabalhar, também, no IESAE-FGV.

Pesquisando a história do IESAE-FGV, ${ }^{6}$ percebemos que a atuação de Durmeval Trigueiro Mendes foi marcante. Em 1972, apresentou proposta de um programa de pesquisa a ser desenvolvido no mestrado, apoiando-se em três postulados básicos:

a) desenvolver-se em função da política educacional e do progresso das ciências da educação no país;

b) compreender, além da pesquisa empírica, a obra do pensamento, caracterizada pela reflexão filosófica em busca das raízes de inteligibilidade da educação, de suas categorias e de seu processo, bem como pelo esforço de uma síntese. Síntese que significa, no caso, a integração das ciências entre si, e das ciências com a política educacional, devendo contar, para isso, com a colaboração de filósofos, cientistas (sobretudo nas ciências sociais) e administradores;

c) ser analítica, mas também prospectiva, preocupada não apenas com a explicação das estruturas e

${ }^{6}$ Com a coordenação da autora desta comunicação e com o apoio do Conselho Nacional de Desenvolvimento Científico e Tecnológico (CNPq) foi desenvolvido, de março de 2000 a fevereiro de 2003, no Programa de Estudos e Documentação Educação e Sociedade (PROEDES), da Faculdade de Educação da UFRJ, o Projeto Integrado de Pesquisa “O IESAE-FGV: origens, construção e extinção”. sistemas em funcionamento, mas também, e sobretudo com a indicação de outros modos de pensar requeridos pelo desenvolvimento brasileiro. (Trigueiro Mendes, 1972, p. 250, grifos do original)

Em termos institucionais, para Durmeval a pesquisa deveria centrar-se em suas áreas de concentração: filosofia da educação (incluindo uma parte histórica), administração educacional (no sentido macroestrutural) e psicologia educacional (idem, p. 253). Não significavam, porém, três disciplinas, mas três campos bastante abrangentes, cuja integração poderia oferecer uma base para o trabalho interdisciplinar, desde que procurasse incorporar, sempre que necessário, a contribuição de pesquisadores de outros institutos, dentro e fora da FGV. Com base nessa diretriz, defendia a existência de duas grandes linhas de pesquisa: uma motivada pelas necessidades e outra requerida pelos programas do curso. A primeira estaria ligada à realidade dos fatos, enquanto a segunda se ordenaria de acordo com a lógica e o ritmo do currículo (idem, ibidem).

Em sua atuação como professor e pesquisador, Durmeval realiza magistralmente essa concepção de pós-graduação com a experiência da disciplina e da pesquisa filosofia da educação brasileira. Sistematizada em meados de 1971, essa disciplina surge

[...] na tentativa de penetrar a espessura da cultura e da política, no Brasil, permeada pela história - diferente da disciplina Filosofia da Educação no Brasil, cuja perspectiva se delineia, há muito tempo, no repertório histórico, puxado, às vezes, pela legislação, ou no panorama das correntes da filosofia da educação, às vezes freqüentadas no exterior, mas imantadas no Brasil sob a forma de “abstração” retirada do contexto brasileiro. (Trigueiro Mendes, 1983, p. 9)

Como base para essa disciplina, Durmeval elaborou um projeto de pesquisa também intitulado Filosofia da educação brasileira, que foi desenvolvido por uma equipe constituída por docentes e pesquisadores de várias instituições, com sua coordenação e 
com o apoio do INEP, no período de 1977 a 1979. A partir de um roteiro básico e de uma estratégia de ação, o projeto apoiava-se em três itens fundamentais: tendências e correntes da educação brasileira; fins e valores, destacando a ideologia, a tecnologia e a cultura brasileira; e planejamento educacional e desenvolvimento social. Como coordenador, procurou reunir de forma articulada vertentes e abordagens diferentes da educação brasileira (idem, p. 14-15). ${ }^{7}$

Segundo Durmeval, a filosofia da educação brasileira, criada por ele no IESAE-FGV, como disciplina era bastante nova. Essa concepção original da filosofia da educação brasileira muito contribuiu para a constituição de uma disciplina acadêmica, mas também inovou, sobretudo pela pesquisa a ela integrada, na crítica das tendências e correntes da educação brasileira, exigindo que se pesquisasse e analisasse em profundidade o processo da educação e os fundamentos do planejamento educacional (Fundação..., 1992, p. 2).

Não resta dúvida de que a contribuição desse educador foi relevante para o IESAE-FGV. Considerando o que se reflete em sua prática de ensino e atentando para o depoimento de alguns de seus orientandos, pode-se dizer que o trabalho então desenvolvido constitui apenas uma amostra de outros realizados com pós-graduandos, de diferentes períodos, marcados por suas aulas e seminários, seus escritos e por uma efetiva orientação acadêmica. Como observa Clarice Nunes, ${ }^{8}$ Durmeval procurava travar sem-

${ }^{7}$ A equipe que se manteve até o final da pesquisa era constituída por: Alfredo Bosi (Universidade de São Paulo - USP), Dermeval Saviani (Universidade Estadual de Campinas - UNICAMP), José Silvério Baía Horta (IESAE-FGV), Antonio Chizzotti (PUC-SP) e Durmeval Trigueiro Mendes como coordenador (IESAE-FGV e UFRJ). Os estudos que resultaram desse projeto foram publicados pela editora Civilização Brasileira em 1983 no livro Filosofia da educação brasileira, considerado uma obra de referência na área de educação até os dias atuais, encontrando-se na $6^{\text {a }}$ edição.

${ }^{8}$ Clarice Nunes, com a orientação de Durmeval Trigueiro Mendes, defendeu a dissertação A modernização do ginásio e a pre um contato intelectual com o pós-graduando, levando-o a perceber

[...] a pós-graduação em educação como uma prática da produção científica, um estímulo à investigação nova e criativa, numa atitude de responsabilidade assumida com o pensamento educacional brasileiro e com o processo de democratização da sociedade e das instituições de ensino em todos os níveis. (Nunes, 1990, p. 175-181)

\section{Durmeval insistia:}

Quanto ao ensino, não é necessário lembrar que a característica essencial da pós-graduação é a elaboração, e não a informação. Ela consiste no trabalho autônomo do pós-graduando (mesmo em equipe), sob a orientação de professores (sobretudo do professor orientador) e em forma de pesquisa. Em vez de absorverem um saber feito, os alunos serão levados a fazê-lo por conta própria. De resto, a pesquisa é inerente também ao ensino graduado (e a qualquer nível de ensino), mas enquanto nos outros níveis ela consiste, apenas, no processo de re-fazer o saber [...] no ensino pós-graduado se trata de fazer avançar o saber, seja incorporando a ele novas "zonas” da realidade, seja construindo outros padrões teóricos, seja ampliando o nível de percepção teórica dos alunos [...]. (Trigueiro Mendes, 1972, p. 257, grifos do original)

Outro orientando seu, José Paulino da Silva, é enfático: "Sua autoridade de mestre não se fundamentava apenas na amplitude de seu conhecimento, na sua produção científica e dedicação profissional: residia sobretudo no seu intransigente senso de justiça e de honestidade intelectual” (1988, p. 89). ${ }^{9}$ Mas se, por um lado, era um pensador e educador crítico e severo

manutenção da ordem, em 1979, no IESAE. Esse estudo foi publicado com o título Escola e dependência: o ensino secundário e a manutenção da ordem, Rio de Janeiro, Achiamé, 1980.

${ }^{9}$ Com a orientação de Durmeval, José Paulino da Silva defendeu, também em 1979, sua dissertação de mestrado, Um estudo sobre a autonomia da universidade brasileira. 
em relação a seus alunos, especialmente com seus orientandos, era também aberto ao diálogo e tolerante, permitindo, como observa Nunes, vôos e tateios que davam chance de aprendizagem e de se viajar por outros pensamentos, construindo o seu próprio com seus esquemas de referência (Nunes, 1990, p. 176).

Com Horta (1990, p. 71s), podemos afirmar que a concepção de ensino e pesquisa na pós-graduação foi mais bem sistematizada por Durmeval quando ele se viu frente ao desafio de elaborar o projeto do IESAE-FGV; mas ele continuou defendendo-a e explicitando-a em outros mestrados.

\section{Durmeval na pós-graduação em educação da UFRJ}

Após ser reintegrado no serviço público, a partir de 1980, juntamente com outras eminentes personalidades de nossa história, exilado no próprio país, Durmeval aceita o desafio de recomeçar. Como professor titular na Faculdade de Educação, trabalha no Departamento de Sociologia da Educação, e depois, como preferiu, no Departamento de História e Filosofia da Educação, de 1980 a 1987, quando veio a falecer. Logo após sua reintegração na UFRJ, elaborou um documento básico sobre os currículos de pedagogia e de formação pedagógica para os cursos de licenciatura, no qual deixa claro ser necessário “formar profissionais de educação para os grandes desafios da época” (Teves, 1990, p. 210). Chama a atenção para a incoerência nas propostas curriculares em curso entre os fins e os meios enunciados e, de forma clara, centra sua análise contra a posição tecnoburocrática então presente na política educacional brasileira. Como docente-pesquisador nessa faculdade, apresentou também um projeto integrado de pesquisa sobre "O INEP e a produção intelectual através da Revista Brasileira de Estudos Pedagógicos”, que não chegou a ser desenvolvido por falta de apoio das agências de fomento.

Nessa nova fase, passou a atuar mais especificamente com o programa de pós-graduação em educação, particularmente no curso de doutorado em educação brasileira. Como docente-pesquisador centrou-se, especialmente, nas questões relativas ao "saber e poder na cultura e na educação brasileira”, pesquisando "o pensamento educacional no Brasil”, pelos enfoques histórico, filosófico e sociológico. A essa linha de pesquisa dedicou-se até 1987, chegando a elaborar um projeto de pesquisa sobre "O saber e o poder na cultura e na educação”. Nesse ano, engajou-se também como consultor na pesquisa "Faculdade Nacional de Filosofia: resgate de uma história”"10 (Soares, 1988, p. 87).

Após sua morte, foi realizado um seminário, como parte das comemorações do vigésimo aniversário da Faculdade de Educação da UFRJ (19681988), pelo Departamento de História e Filosofia da Educação e pela Diretoria Adjunta da Graduação, tendo como tema "O pensamento de Durmeval Trigueiro” (Trigueiro Mendes, 1990). O seminário ocorreu nos dias 23 e 24 de novembro de 1988 e teve como objetivo resgatar a memória desse educador, como também refletir sobre suas idéias e contribuições no campo da educação. Para tanto, contou com a participação não somente de professores e pósgraduandos dessa faculdade, mas também de docentes-pesquisadores de outras instituições do Rio de Janeiro, que tiveram o privilégio de trabalhar com Durmeval, como partícipes e estudiosos de sua obra. O seminário foi encerrado pelo reitor da UFRJ, que fez a entrega, post-mortem, do título de professor emérito da UFRJ, recebido por sua viúva, professora Maria Márcia Trigueiro Mendes.

Em suma, a expressiva contribuição de Durmeval Trigueiro Mendes, nos programas de pós-graduação em que atuou, foi mostrar a necessidade de

${ }^{10}$ Essa pesquisa foi desenvolvida na Faculdade de Educação, contando com a participação de vários professores e pósgraduandos, coordenada por Maria de Lourdes de Albuquerque Fávero, cujos resultados e seu acervo, constituído, atualmente, por mais de cem mil documentos, deu origem à criação do PROEDES, na Faculdade de Educação da UFRJ. 
[...] substituir uma administração burocrática da educação por uma educação técnica, e um ensino rotineiro alienado por um ensino capaz de produzir uma visão crítica da educação. Por ambas as razões, há necessidade permanente da pesquisa educacional, que constitui a própria substância da pós-graduação. (Trigueiro Mendes, 1972, p. 249)

Para Durmeval, se a pós-graduação deveria ser organizada como espaço de pesquisa e ensino, um curso de pós-graduação "não deveria ser organizado, predominantemente, em termos de aulas, mas de pesquisas e seminários, destinando-se as aulas, basicamente, a trabalhos de orientação geral e síntese teórica” (idem, p. 257). Nessa perspectiva, ele vai além, quando observa que, “em qualquer hipótese, o essencial é evitar a burocratização do curso; é fazê-lo desenvolver-se dentro de uma atmosfera criadora” (idem, p. 258).

De forma explícita, ele deixa ainda mais clara sua posição ao afirmar:

[...] temos de reconhecer que a pedagogia é, antes de tudo, liberdade de olhar. Deixar ver, deixar expressar-se, consentir no tateamento, na busca fora dos trilhos dogmáticos, reconhecer-se cada um enfeudado numa visão a longo termo viciada, que precisa libertar-se pelo contato com outras visões [...]; precisamos resolver a didática, substituindo o método que institucionaliza a indução do professor-aluno pelo método que promove o encontro dos dois no espaço da consciência interrogativa. (Trigueiro Mendes, 1973, p. 230-231)

\section{Observações inacabadas}

Convivendo com Durmeval Trigueiro Mendes e compulsando seus escritos, percebemos tratar-se, antes de tudo, de um filósofo dedicado, em diferentes momentos de sua vida, às tarefas concretas da educação, nelas intervindo como trabalhador do ensino, procurando integrar suas idéias a respeito da educação e da universidade, num discurso articulado e operante (Fávero, 2002).

No desdobrar-se em múltiplas tarefas, o melhor de seus esforços foi canalizado para o mundo acadêmico e para a universidade, especialmente para os programas de pós-graduação em educação, nos quais atuou como professor, pesquisador e mestre de mestres. Daí constituir-se referência sempre presente, quando pensamos universidade e pós-graduação em educação, ontem e hoje. É difícil nos determos nessas questões sem nos remetermos a outra questão essencial, objeto de muitas de suas reflexões: o ensino e a pesquisa, e seu significado de busca de um novo “cogito instaurador" (Trigueiro Mendes, 1975, p. 16).

Acreditamos que a marca mais profunda desse pensador/educador consistiu no fato de que ele vivia a fundo suas convicções, o que se expressa na vitalidade de suas propostas e na coerência entre o pensar e o agir. "Desfrutou do poder, sem jamais se deixar levar pelos seus atrativos” (Saviani, 1983, p. 29). Ao contrário, sua experiência nos cargos e funções públicas o converteu num dos críticos mais autorizados de nosso sistema educacional e da tecnoburocracia, que se tornou hegemônica ao longo de décadas na história recente do país.

Parodiando o mestre, ocorre-nos afirmar: a criação, o aperfeiçoamento do universo acadêmico, tanto no nível da graduação quanto no da pós-graduação, é um exaustivo empreendimento, um processo em permanente construção, um trabalho desafiador, jamais uma festa (Trigueiro Mendes, 1968).

MARIA DE LOURDES DE ALBUQUERQUE FÁVERO, livre-docente pela Pontifícia Universidade Católica (PUC-Rio), em 1976, é atualmente professora titular e coordenadora do Mestrado em Educação da Universidade Católica de Petrópolis (UCP). Como professora aposentada da Universidade Federal do Rio de Janeiro (UFRJ), fundou em 1987 e coordena até hoje o Programa de Estudos e Documentação “Educação e Sociedade” (PROEDES) dessa Universidade. Além de vários artigos em periódicos e capítulos em livros, como resultados de pesquisas realizadas nesse programa, publicou: Da universidade modernizada à universidade disciplinada: Atcon e Meira Mattos ( São Paulo: Cortez; Campinas: Autores Associados, 1991); A UNE em tempos de autoritarismo (Rio de Janeiro: Ed. UFRJ, 1995); Universidade do Brasil: das 
origens à construção e Universidade do Brasil: guia dos dispositivos legais (ambos pela Ed. UFRJ, 2000). Coordenou ainda a produção dos cinco volumes da série Faculdade Nacional de Filosofia (Ed. UFRJ, vol. 1 a 4 em 1989 e vol. 5 em 1992); com Jader Medeiros Britto, a elaboração e a organização do Dicionário de Educadores no Brasil: da Colônia aos dias atuais, cuja segunda edição, com verbetes sobre 144 educadores e mais de 1.000 páginas, foi publicada em 2002 pela Ed. UFRJ com apoio do Ministério da Educação/Instituto Nacional de Estudos e Pesquisas Educacionais Anísio Teixeira (MEC/INEP); e com Deise Mancebo, Universidade: políticas, avaliação e trabalho docente, publicado em 2005 pela Cortez Editora.

\section{Referências bibliográficas}

CARVALHO, José Carmelo, FÁVERO, Osmar, (1986). A área de planejamento educacional no mestrado da PUC-Rio. In: PONTIFÍCIA UNIVERSIDADE CATÓLICA DO RIO DE JANEIRO. Vinte anos de mestrado em educação. Rio de Janeiro, 9p, (mimeo.).

FACULDADE DE EDUCAÇÃO DA UNIVERSIDADE FEDERAL DO RIO DE JANEIRO, (1969). In: REUNIÃO DO CONSELHO DEPARTAMENTAL DA FACULDADE DE EDUCAÇÃO, 23., 1969. Atas... p. 32-33.

FÁVERO, Maria de Lourdes de A., (2002). Durmeval Trigueiro Mendes e seu pensamento prospectivo. In: GARCIA, Walter E. (org.). Educadores brasileiros do século XX - v. 1. Brasília: Plano, p. 93-113.

FÁVERO, Osmar, (1990). Concepção de política e planejamento educacional. In: TRIGUEIRO MENDES, Durmeval. Filosofia política da educação brasileira. Rio de Janeiro: Fundação Universitária José Bonifácio, p. 57-69.

(2000). Apresentação: para uma teoria do planejamento educacional brasileiro. In: TRIGUEIRO MENDES, Durmeval. O planejamento educacional no Brasil. Rio de Janeiro: EDUERJ, p. 7-16.

FUNDAÇÃO GETÚLIO VARGAS, (1971). Portaria $n^{\circ}$ 33, de $1^{\circ}$ de junho de 1971. Cria o Instituto de Estudos Avançados em Educação (IESAE) e designa seu Diretor e a Comissão de Planejamento e Programação do Instituto. , (1971). ATA DA SESSÃO DE ABERTURA DOS

TRABALHOS DO IESAE, realizada em $1^{\circ}$ de julho. (1992). Proposta de reestruturação do IESAE. $1^{\circ}$ Documento. Rio de Janeiro, jan., 14p. (mimeo.).
HORTA, José Silvério Baía, (1975). O Conselho Federal de Educação e o planejamento educacional no Brasil. Dissertação de mestrado. Pontifícia Universidade Católica do Rio de Janeiro.

, (1990). A concepção de ensino e pesquisa de filosofia da educação brasileira em Durmeval Trigueiro Mendes. In: TRIGUEIRO MENDES, Durmeval. Filosofia política da educação brasileira. Rio de Janeiro: Fundação Universitária José Bonifácio, p. 71-77.

MIRANDA, Vera Marina, (1974). Planejamento educacional e política econômica. Dissertação de mestrado. Pontifícia Universidade Católica de São Paulo.

NUNES, Clarice, (1990). Autonomia de pensamento: o legado de Durmeval Trigueiro Mendes. In: TRIGUEIRO MENDES, Durmeval. Filosofia política da educação brasileira. Rio de Janeiro: Fundação Universitária José Bonifácio, p. $175-181$.

PONTIFÍCIA UNIVERSIDADE CATÓLICA DO RIO DE JANEIRO, (1986). Proposta de Seminário. Vinte anos do mestrado em educação da PUC-Rio. Rio de Janeiro, Departamento de Educação da PUC-Rio, abr., p. 1 (mimeo.).

SAVIANI, Dermeval, (1983). Entrevistando Durmeval Trigueiro. Revista ANDE, São Paulo, ano 3, nº 6, p. 29, ago.

SILVA, José Paulino da, (1988). Durmeval Trigueiro Mendes: o mestre e amigo. In: TRIGUEIRO MENDES, Durmeval. Concepção do educador e da universidade. João Pessoa: UFPB, p. 89-91.

SOARES, Gilda Maria F. Benevides, (1988). Atuação de Durmeval na Faculdade de Educação da UFRJ. In: TRIGUEIRO MENDES, Durmeval. Concepção do educador e da universidade. João Pessoa: UFPB, p. 87-88.

TEVES, Nilda, (1990). O cotidiano acadêmico de Durmeval Trigueiro. In: TRIGUEIRO MENDES, Durmeval. Filosofia política da educação brasileira. Rio de Janeiro: Fundação Universitária José Bonifácio, p. 207-213.

TRIGUEIRO MENDES, Durmeval, (1968). Expansão do ensino superior no Brasil. Documenta, no 91, set., p. 26-70.

(1972). Pesquisa e ensino no mestrado em educação. Revista Brasileira de Estudos Pedagógicos, v. 58, nº 128, out.-dez., p. 249-264.

(1973). Realidade, experiência e criação. Revista Brasileira de Estudos Pedagógicos, v. 59, nº 130, jul.-set., p. 227-240. 
, (1975). Desenvolvimento, tecnocracia e universidade. Revista de Cultura Vozes, v. 49, nº 6, p. 5-28.

, (1983). Depoimento concedido à Revista ANDE, São Paulo, nº 6, p. 29-35.

, (1990). Seminário: o pensamento de Durmeval Trigueiro. In: TRIGUEIRO MENDES, Durmeval. Filosofia política da educação brasileira. Rio de Janeiro: Fundação Universitária José Bonifácio, p. 41-42.

, (2000). O planejamento educacional no Brasil. Rio de Janeiro: EDUERJ.
, (org.) (1983). Filosofia da educação brasileira. Rio de Janeiro: Civilização Brasileira.

TRIGUEIRO MENDES, Maria Márcia, (1990). Discurso de agradecimento. In: TRIGUEIRO MENDES, Durmeval. Filosofia política da educação brasileira. Rio de Janeiro: Fundação Universitária José Bonifácio, p. 189-191.

Recebido em abril de 2005

Aprovado em maio 2005 


\section{Resumos/Abstracts}

Maria de Lourdes de Albuquerque

Fávero

\section{Durmeval Trigueiro Mendes e sua contribuição à pós-graduação em educação}

Quando nos preparamos para celebrar, em 2006, quarenta anos da normalização da pós-graduação, em sentido estrito, no país, é pertinente registrar a contribuição de um dos educadores que canalizou o melhor de seus esforços para a pós-graduação na área da educação, no período de 1970 a 1987 . Na primeira parte deste trabalho, procuramos destacar o itinerário desse educador/pensador como um intelectual consciente de sua responsabilidade com a construção da educação brasileira e o processo de democratização da educação no país. Na segunda, mostramos como percebia um programa de pósgraduação em educação stricto sensu e sua atuação em programas do Rio de Janeiro. Nos programas em que atuou como docente pesquisador - Pontifícia Universidade Católica do Rio de Janeiro (PUC-Rio), Instituto de Estudos Avançados em Educação da Fundação Getúlio Vargas (IESAE-FGV) e Faculdade de Educação da Universidade Federal do Rio de Janeiro (UFRJ) -, deixou suas marcas ao defender que a pós-graduação deveria buscar conciliar sempre o ensino prático com o teórico, e ao insistir que a pesquisa em educa- ção deveria se caracterizar pela reflexão, em busca de suas raízes, suas categorias e seu processo, bem como pelo esforço de síntese. Afirmamos, enfim, que o melhor dos esforços desse educador foi canalizado para o universo acadêmico, atuando como professor, pesquisador e mestre de mestres.

Palavras-chave: Durmeval Trigueiro Mendes; pós-graduação em educação; ensino e pesquisa

Durmeval Trigueiro Mendes and his contribution to postgraduate studies in education

As we prepare to commemorate forty years of recognised postgraduate studies in Brazil in 2006, it is relevant to register the contribution of one of the educators who channelled the best of his efforts into postgraduate studies in the field of education, in the period between 1970 and 1987. In the first part of this article we seek to trace the itinerary of this educator/thinker as an intellectual aware of his responsibility for the construction of Brazilian education and the process of democratisation of education in the country. In the second part, we demonstrate how he perceived a postgraduate programme in education and his participation in programmes in Rio de Janeiro. In those programmes in which he participated as lecturer and researcher - the Pontificate Catholic University of Rio de Janeiro (PUC-Rio), the Institute of Advanced Studies in
Education at the Getúlio Vargas Foundation (IESAE-FGV) and the Faculty of Education of the Federal University of Rio de Janeiro (UFRJ) he left his mark by defending that postgraduate studies should always seek to conciliate practical teaching with theory, and by insisting that research in education should be characterised by reflection on its roots, its categories and its process, as well as the search for synthesis. We conclude by affirming that the best efforts of this educator were dedicated to the academic world in his role as lecturer, researcher and teacher of teachers.

Key-words: Durmeval Trigueiro Mendes; postgraduate studies in education; teaching and research 